\title{
Digital controller design considering hardware constraints: application in a paraplegic patient
}

\author{
Marcelo Augusto Assunção Sanches, Ruberlei Gaino*, Renan Fernandes Kozan, Marcelo Carvalho \\ Minhoto Teixeira, Aparecido Augusto de Carvalho, Márcio Roberto Covacic, Carlos Antonio Alves, \\ Mateus Fernandes Réu Urban, Marcos Vinícius Nascimento Junqueira, Rodrigo Cardim, Edvaldo \\ Assunção, Edno Gentilho Junior
}

\begin{abstract}
Introduction: A methodology was developed for implementing closed-loop control algorithms and for evaluating the behavior of a system, considering certain component restrictions used in laboratory implementation. Methods: Mathematical functions representing a model of the biological system were used for knee extension/flexion movements. A Proportional Integral Derivative (PID) controller and another one using the root locus method were designed to control a patient's leg position by applying functional electrical stimulation (FES). The controllers were simulated in Matlab and ISIS Proteus. After the simulations were performed, the codes were embedded in a microcontroller, and tests were conducted on a paraplegic volunteer. To the best of the authors' knowledge, this is the first time that ISIS Proteus software resources have been used prior to implementing a closed-loop system designed to control the leg position of patients. Results: This method obviates the application of initial controller tests directly to patients. The response obtained in the experiment with a paraplegic patient complied with the specifications set in terms of the steady-state error, the settling time, and the percentage overshoot. The proposed procedure was successfully applied for the implementation of a controller used to control the leg position of a paraplegic person by electrical muscle stimulation. Conclusion: The methodology presented in this manuscript can contribute to the implementation of analog and digital controllers because hardware limitations are typically not taken into account in the design of controllers.
\end{abstract}

Keywords Digital controller, Microcontroller, ISIS Proteus, PID controller, Functional Electrical Stimulation (FES), Paraplegic.

\section{Introduction}

After a spinal cord injury that significantly affects the movement of the lower limbs, the large thigh muscles atrophy quickly, as reflected in the level of activity of organs such as the heart and lungs. As a result, the health of the affected individual dramatically worsen.

Electrical signals applied at suitable levels to the skin surface of individuals can be as effective for muscle strengthening as a voluntary muscle contraction (Lieber et al. 1996). However, the electrical signal parameters must be adjusted properly to create smooth movements in the stimulated limb and avoid hyperstimulation, which can generate muscle fatigue and discomfort in the patient (Mohammed et al., 1997).

Electrical stimulation is generally conducted in an open loop with steady signal parameters (amplitude, frequency and pulse width). Thereby, the energy level applied at the beginning of the movement to overcome the inertia of the lower limb is not reduced during the ensuing angular movement. Using closed-loop controllers, the signal parameters of the electrical stimulation can be more precisely adjusted (Crago et al., 1980), providing better control of the movements and delaying the fatigue of the stimulated muscles.
To simulate a leg position controller, a mathematical model that relates the applied electrical stimulus to the dynamics of knee extension movement must be developed. Law and Shields (2006) presented a comparison of three classic mathematical models, one simplified linear model and two non-linear models, proposed by Bobet and Stein (1998) and by Huxley (1957).

Comparing the computational simulation results of these three models with the results of experiments involving four patients, Law and Shields (2006) concluded that the Huxley model (1957) most closely approximated the actual motion of the knee, followed by the model developed by Bobet and Stein (1998). However, for some low-frequency stimuli, the linear and the non-linear models presented similar performance.

The dynamics of a muscle subjected to electrical stimulation are non-linear, and closed-loop control requires highly complex and efficient techniques (Hatze, 1981). Some researchers have proposed mathematical models of knee extension movement, for instance, Deaecto (2005), Ferrarin and Pedotti (2000), Gaino (2007, 2011), Prado (2009) and Teixeira et al. (2007), among others.

*e-mail: ruberlei.gaino@gmail.com, rgaino@uel.br Received: 05 March 2013 / Accepted: 19 May 2014 
Gaino (2009) and Teixeira et al. (2006) presented, for the first time, non-linear mathematical models that relate electrical stimuli to the dynamics of knee extension movement, represented by Takagi-Sugeno fuzzy models, whose main function is to describe non-linear systems as a convex combination of linear systems.

Currently, almost all control systems implemented are based on systems controlled by computers. Essentially, such systems consists of a real process (analog plant), a processed digital system, and digitalto-analog (D/A) and analog-to-digital (A/D) converters.

The implementation of a controller is usually not simple because controller operation covers several areas, concepts and platforms. The controller may prove efficient in simulations, but its implementation may not be feasible. One example is the case of microcontrollers because such controllers have limitations with respect to the accuracy of A/D conversion, speed processing, memory capacity, variables involved in calculations, etc. Thus, considering the other components of a real controller as well, a simulation model that does not produce suitable data that reflect real experiences may be obtained (Prado, 2009).

The leg movement control of paraplegic patients produced by muscular electrical stimulation is very important in rehabilitation engineering, and many researchers have performed studies in this area, such as Ferrarin and Pedotti (2000), Ferrarin et al. (2001), Law and Shields (2006) and Lieber (1996). In 2010, Brazil had 13,273,969 people with motor disabilities according to the IBGE (Blog do Deficiente Físico, 2012). The IBGE did not report the number of paraplegic, hemiplegic, and quadriplegic individuals. In the USA, alarmingly, 11,000 new cases of spinal cord lesions are reported each year, $52 \%$ of which are related to paraplegics (SCI-INFO, 2009).

The aim of this study was to develop a new methodology using ISIS Proteus software for the simulation and evaluation of leg movement controllers in patients using electrical stimulation. To the best of our knowledge, based on available scientific data, ISIS Proteus was used for the first time as a development environment for a closed-loop system implementation with the goal of controlling the leg position of a paraplegic patient. With this software, the user can simulate controllers' circuits composed of a wide variety of commercial microcontrollers, amplifiers, converters and other components. The devices' parameters are incorporated into the simulations, enabling the designer to determine whether the controller performance meets the project specifications.

A relevant aspect to be highlighted in this paper is the use of the ISIS Proteus software program as a basis for testing digital control designs, aiming at conducting preliminary tests for verification and validation of the control theory applied to the mathematical model of knee joint of paraplegic patients, providing the possibility to observe initial errors in the control codes to be embedded in the microcontrollers and eliminating all errors before patient tests.

The Proteus environment can be extremely useful in accelerating the research and development of controller prototypes. In applications that involve tests with patients, it is possible to make all the necessary adjustments before the first test using hardware is conducted.

\section{Methods}

The ISIS Proteus software program was used as the project basis, which allowed for control tools and electronic instrumentation to be combined in a single platform, emulating the implementation conditions of real controllers (Gaino, 2008; Prado, 2009; Sanches, 2010).

The controller simulations were initially performed in Matlab. The codes were then converted to the C language and embedded in a microcontroller of the ISIS Proteus program. The goal of the Matlab simulation was to mathematically validate the control model; however, as mentioned in the previous section, the simulation did not take into consideration the controller components' hardware restrictions.

The following sequence was adopted for the controllers' design:

- The choice of a mathematical model that relates an electrical stimulus with the dynamics of knee extension movement;

- Identification of the parameters and/or linearization of the mathematical model;

- Design of the controller;

- Discretization, when the controller is described by differential equations;

- Representation of the controller using difference equations;

- Simulation of the discrete controller in Matlab and then in the ISIS Proteus environment;

- Implementation of the discrete controller using a microcontroller and other simulated components in ISIS Proteus;

- Execution of tests with a paraplegic volunteer.

To perform experimental tests such as the identification of parameters and closed-loop control, an instrumented chair with an electrogoniometer, an accelerometer and a gyroscope (Figure 1) was developed. The figure shows how the electrodes were placed on the patient's thigh, with an off switch held in the volunteer's hand. This device enabled the volunteer to immediately interrupt the test when he deemed it necessary. 


\section{Knee joint models}

Three models, linear, non-linear and linearized, that relate an electrical stimulus with the dynamics of knee extension movement were used.

\section{Linear knee joint model}

The linear mathematical model chosen, based on the studies of Law and Shields (2006), was a transfer function with two poles and no zeroes.

Parameter identification was performed based on experimental tests with a paraplegic volunteer, following the procedure described by Ferrarin and Pedotti (2000). A step input signal ( $u$, electrical stimulation) was applied to the patient, and the corresponding output signal ( $\theta_{v}$, angle between the tibia and the vertical axis on the sagittal plan) was analyzed.

A 40-year-old paraplegic volunteer with complete spinal cord lesion at level T6 was positioned in the instrumented chair (Figure 1), maintaining an angle of approximately $130^{\circ}$ between the trunk and thigh (Andreoni et al., 1996; Griffin, 1978). Two surface electrodes $(4 \times 4 \mathrm{~cm})$ were used, one at the proximal insertion of the quadriceps area and the other in the distal insertion region, close to the patella (Ferrarin and Pedotti, 2000).

An electric current with a balanced, biphasic, rectangular waveform with a pulse width of $220 \mu \mathrm{s}$ was applied to the skin surface of the volunteer. The signal amplitude was then held constant for 3 seconds and considered a step pattern (Ferrarin and Pedotti, 2000). The pulse amplitude was adjusted to obtain an incomplete knee extension, reaching a maximum angle of $70^{\circ}$ with respect to the initial rest position. The frequency of the signal was $50 \mathrm{~Hz}$ (Ferrarin and

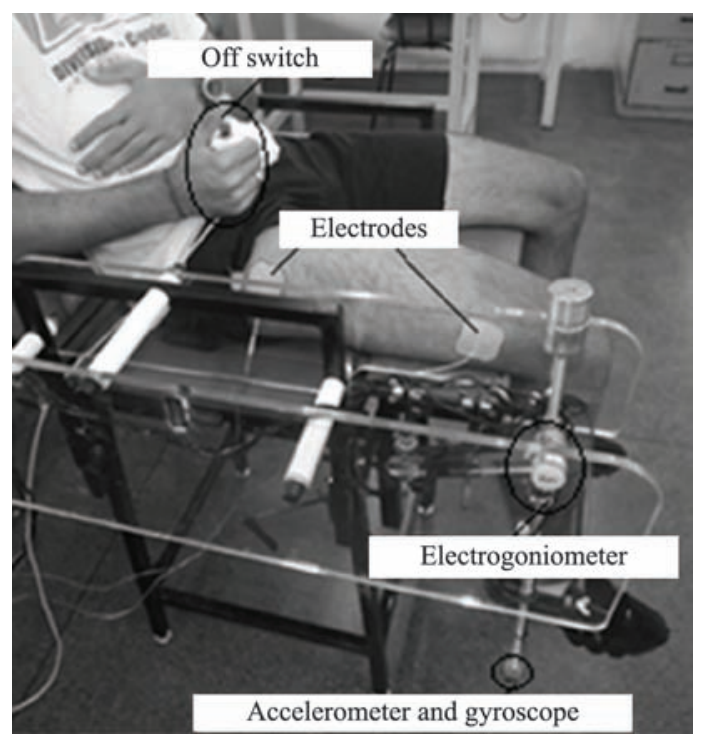

Figure 1. Volunteer positioned in the instrumented chair.
Pedotti, 2000). For healthy persons, currents with amplitudes in the range of 60-80 mA are usually used, but in paraplegic patients, currents can reach $120 \mathrm{~mA}$. Figure 2 shows the waveform of the applied signal.

After the electrical stimulation and the simultaneous acquisition of the input and output signals, the parameters of the transfer function were assessed. This function was defined as a reference to obtain the mathematical model parameters and related the electrical stimulus (input) to the position of the volunteer's leg (output). The assessment was obtained using the "Transfer Function Estimation" function of the LabVIEW program (National Instruments).

Thus, the following transfer function was obtained:

$$
\frac{\theta_{v}(s)}{u(s)}=\frac{45.59}{0.06803 s^{2}+0.5265 s+1}
$$

\section{Design of the controller and linear model}

The first controller used was the PID, which is widely used to control various processes and plants.

Stability restrictions and the following restrictions on a step-type input were incorporated into the control system design: (i) a settling time of less than 2 seconds (the same used in tests performed by Ferrarin and Pedotti (2000)); (ii) a percentage overshoot (PO) of less than $20 \%$ (thus, the knee maximum extension would not be reached); (iii) a null steady-state error (allowing the leg angle to be as close to the specified value as possible).

We used the pole allocation method, which aims to cancel the poles of the plant, following the steps and algorithms described by Prado (2009). The controller was projected in discrete time and the gains $K_{\mathrm{p}}=0.02685, K_{\mathrm{i}}=0.077938$, and $K_{\mathrm{d}}=0.000457$ were inserted. Certain project constraints were used to evaluate the control system output considering the hardware limitations incorporated.

\section{Discretization and linear model}

To insert the transfer functions of the controller and the plant in microcontrollers, it is necessary that their equations be in the discrete-time domain.

The controller parameters were designed in the discrete-time domain. By discretizing the PID

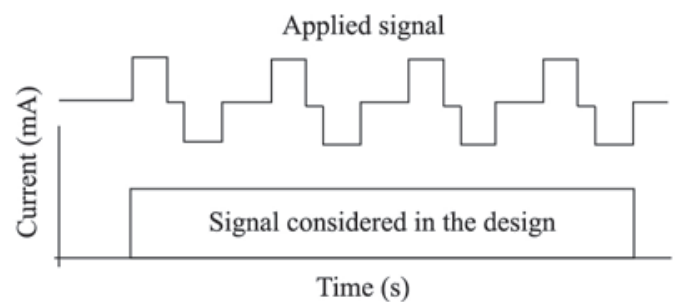

Figure 2. Signal with step features. 
equation and inserting the calculated gains, the following equation is obtained:

$$
u\left(K T_{s}\right)=K_{p} e\left(K T_{s}\right)+I\left(K T_{s}\right)+\frac{K_{d}}{T_{s}}\left[e\left(K T_{s}\right)-e(K-1) T_{s}\right]
$$

where

$K_{\mathrm{p}}$ is the proportional gain;

$K_{\mathrm{i}}$ is the integral gain;

$K_{\mathrm{d}}$ is the derivative gain;

$e(K)$ is the error between the input and the output defined in Figure 3

$e(K-1)$ is the previous error;

$I\left(K T_{s}\right)=I\left((K-1) T_{s}\right)+K_{i} e\left(K T_{s}\right)$;

$\mathrm{T}_{\mathrm{s}}$ is the sampling period.

In the next step, we investigated the response of the controller designed for an input that positions the leg in a $30^{\circ}$ angle $(0.52 \mathrm{rad})$. The control system was simulated in the Matlab/Simulink environment. The control system elements and the plant are presented in Figure 3.

The system consists of an error detector with output $\mathrm{e}(\mathrm{s})$, which calculates the difference between the unit step input and the output $\theta_{\mathrm{v}}(\mathrm{s})$ of the plant; an A/D converter; a discrete controller; and a D/A converter that provide the signal $\mathrm{u}(\mathrm{s})$ calculated by Equation 2 .

\section{Insertion of the system in the ISIS Proteus and linear model}

Simulations on this platform can be performed in various ways:

- Controller inserted in a microcontroller and the mathematical model of the knee joint (plant) in a block;

- Controller inserted in a microcontroller and the plant represented by its transfer function;

- Controller inserted in a microcontroller and the plant in another microcontroller;

- Controller and plant inserted in the same microcontroller.

To simulate the system on the ISIS Proteus platform, the control law indicated by Equation 2 was incorporated into a microcontroller, with the plant represented by its transfer function. This simulation verifies whether the control law and the hardware are suitable before they are tested with a paraplegic volunteer, during which the plant is replaced by the volunteer's leg. Figure 4 presents the system simulated in Proteus ISIS.
The main elements of the system are a microcontroller with an A/D (U1) converter, a D/A (DAC1) converter, a block with the transfer function of the plant (MUSCLE) that mathematically represents the ratio between the electrical stimulation and the angular position of the volunteer's leg, an oscilloscope, power supplies and LEDs.

The program that controls the entire system was inserted in the microcontroller. The program is composed of two parts. In the first part, the internal registers of the microcontrollers are set up, such as the INTCON, which controls interrupts; the ADCON, which is responsible for the A/D converters; the TMR, which is responsible for the time basis; and the TRIS that controls the input and output ports. If these registers are not set up properly, the program will not operate correctly when embedded into the microcontroller. In the second part of the program, Equation 2 is inserted in the microcontroller.

\section{Non-linear model of the knee joint}

The Ferrarin and Pedotti (2000) non-linear model was adopted because it provides a mathematical expression that relates the torque produced in the lower limb with the pulse width applied. In this model, the authors considered the lower limb as an open cinematic chain composed of two rigid segments, the thigh and the tibia-foot set, as illustrated in Figure 5.

The thigh was considered to be stationary; thus, only the dynamics of the tibia-foot joint were considered in the model, which only allows flexion/ extension movements of the knee.

The passive behaviors of the muscle-tendon complex of the knee joint were obtained by considering the sum of a stiffness component $\left(\mathrm{M}_{\mathrm{s}}\right)$ and a damping component $\left(\mathrm{M}_{\mathrm{d}}\right)$, which depend, respectively, on the knee angle $(\theta)$ and angular velocity $\left(\dot{\theta}_{v}\right)$. In this model, the following components were also considered: inertial $\left(\mathrm{M}_{\mathrm{i}}\right)$, gravitational $\left(\mathrm{M}_{\mathrm{g}}\right)$, and the active torque of the knee $\left(\mathrm{M}_{\mathrm{a}}\right)$, which is obtained through the quadriceps stimulation.

The dynamic equilibrium of these components around the knee joint is given by Equation 3 (Ferrarin and Pedotti (2000):

$M_{i}=M_{g}+M_{s}+M_{d}+M_{a}$,

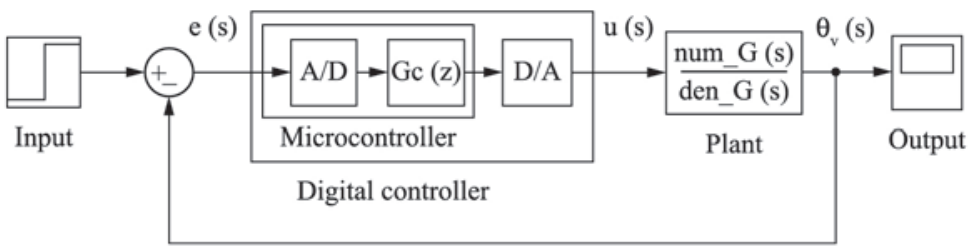

Figure 3. Controller and plant simulated in Matlab. 


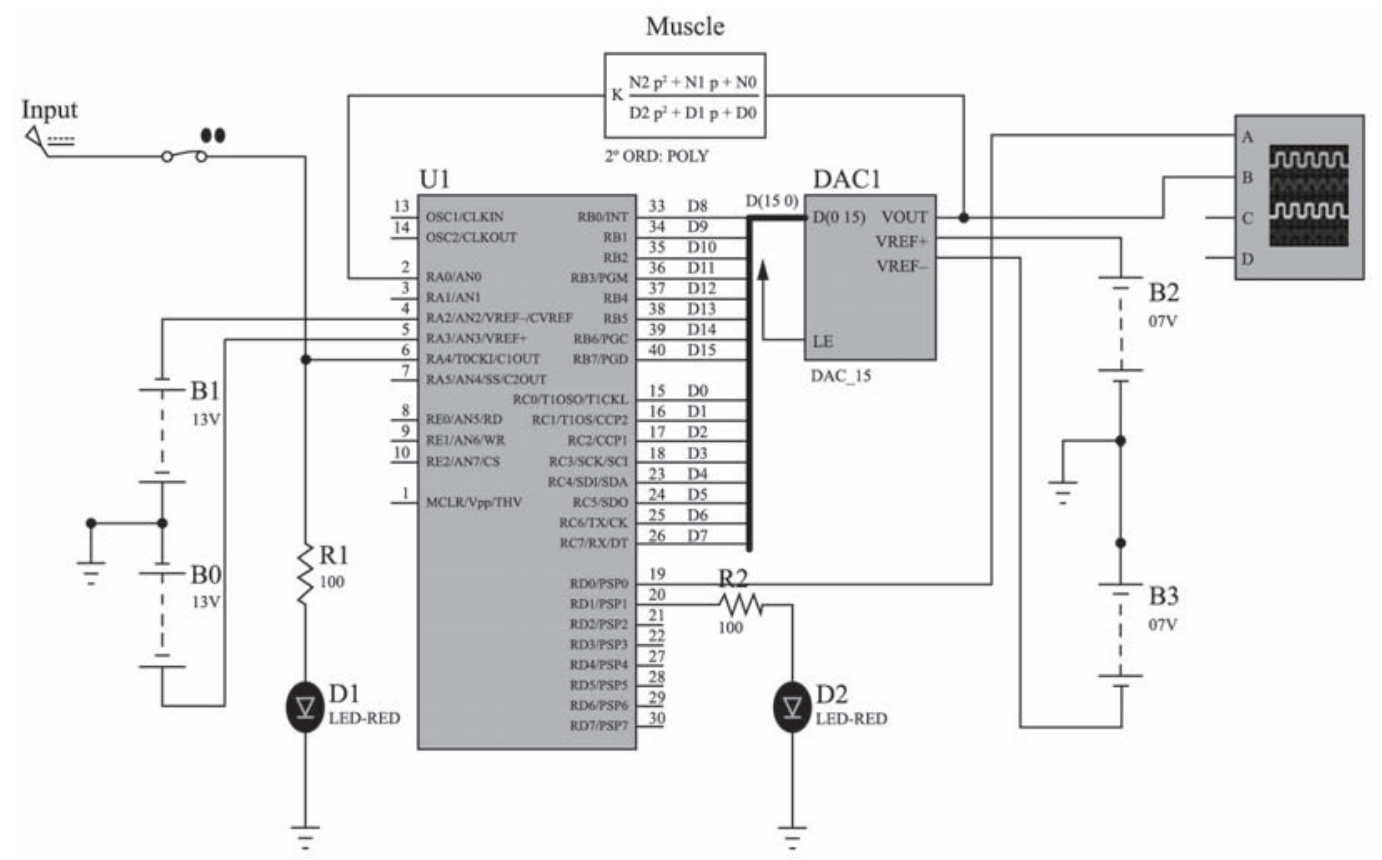

Figure 4. Controller embedded and simulated in ISIS Proteus.

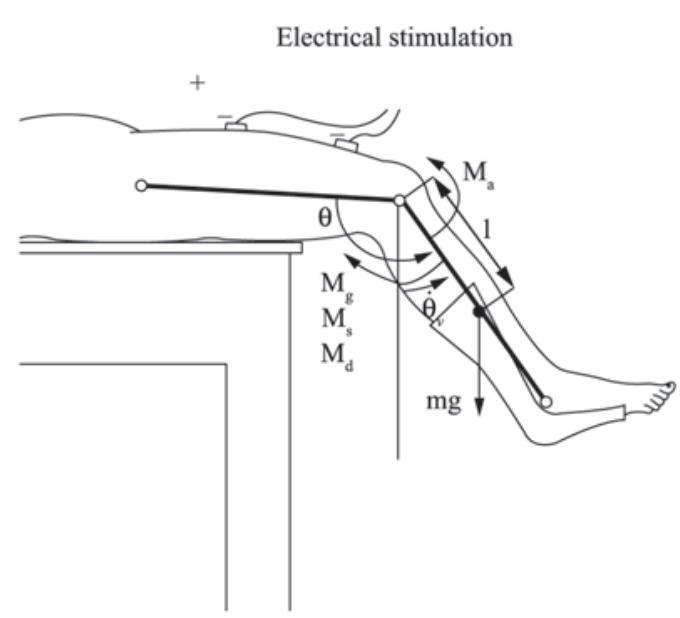

Figure 5. Schematic representation of the lower limb with electrodes on quadriceps and demonstration of certain parameters considered in the modeling.

which can be expressed as follows:

$$
J \ddot{\theta}_{v}=-m g l \operatorname{sen}\left(\theta_{v}\right)-M_{s}-B \dot{\theta}+M_{a}
$$

where

$J$ is the inertial moment of tibia-foot complex; $\theta$ is the knee joint angle (angle between tibia and thigh in the sagittal plane);

$\theta_{v}$ is the tibia angle (angle between tibia and the vertical axis in the sagittal plane); $\ddot{\theta}_{v}$ is the angular acceleration of the tibia; $m$ is the mass of the tibia-foot complex; $l$ is the distance between the knee and the center of mass of the tibia-foot complex;

$B$ is the viscous coefficient.

The torque $\mathrm{M}_{\mathrm{s}}$ due to the joint stiffness component can be expressed as follows (Ferrarin and Pedotti, 2000):

$$
M_{s}=-\lambda e^{-E^{*} \theta}(\theta-\omega)
$$

where

$\lambda, E$ are the coefficients of the exponential term;

$\omega$ is the resting elastic knee angle.

The relationship between the pulse width $(\mathrm{P})$ of the electrical stimulation (input) and the active knee torque ( $\mathrm{M}_{\mathrm{a}}$, output) can be expressed by the following equation:

$$
H(s)=\frac{M_{a}(s)}{P(s)}=\frac{G}{(\tau s+1)}
$$

where

$\mathrm{G}$ is the static gain;

$\tau$ is the time constant.

Based on Equations 4, 5 and 6, the following equation is obtained:

$J \ddot{\theta}_{v}=-\operatorname{mglsen}\left(\theta_{v}\right)-\lambda e^{-E_{\theta}}(\theta-\omega)-B \dot{\theta}+M_{a} \tau \dot{M}_{a}+M_{a}=G P$ 


\section{Linearized model of the knee joint}

Figure 5 shows that $\theta_{v}=\theta+\pi / 2$. Based on the linearization of Equation 4 (Teixeira et al., 2007) at the operating point $\theta_{\mathrm{vo}}=30^{\circ}(0.52 \mathrm{rad})$, the following equation is obtained by considering the parameters of Ferrarin and Pedotti (2000):

$$
\frac{\theta_{v}(s)}{u(s)}=N(s)=\frac{42500}{0.3728 s^{3}+0.6488 s^{2}+10.17 s+10.41}
$$

\section{Design of the controller and linearized model}

The method used in this case was the Root Locus, which allows for the study of the evolution of the roots of an equation when a parameter is varied continuously, thus enabling the determination of this parameter such that the system achieves the desired dynamic behavior (Franklin et al., 2006).

The design specifications were the same as those used in the controller and linear model.

A controller was designed with three zeroes to cancel the existing three poles. One pole was added at the origin (zero), one at -50 to attract the root locus for the region specified that meets the desired transient response region, and the third at -100 so that the controller presented the same number of poles and zeroes. The following equation was obtained:

$$
\frac{u(s)}{e(s)}=N_{c}(s)=1.5 * \frac{0.32728 s^{3}+0.6488 s^{2}+10.17 s+10.41}{s^{3}+150 s^{2}+5000 s}
$$

\section{Discretization and linearized model}

Equation 9 was discretized by the Tustin method (Franklin et al., 2006). Assuming Ts $=0.01 \mathrm{~s}$, the following equation for this discretized controller is obtained:

$$
\frac{u(z)}{e(z)}=N_{c}(z)=1,5 \frac{0.2007 z^{3}-0.5981 z^{2}+0.5946 z-0.1972}{z^{3}-1.933 z^{2}-1,133 z-0.2}
$$

Insertion of the system in the ISIS Proteus and linearized model

The controller was inserted in a microcontroller and the plant represented by its transfer function.

Initially, Equation 10 was converted to the following difference equation:

$$
\begin{aligned}
& \mathrm{u}(\mathrm{k})=\left\{1.5 *\left[\begin{array}{l}
0.2007 \mathrm{e}(\mathrm{k})-0.5981 \mathrm{e}(\mathrm{k}-1)+ \\
0.5946 \mathrm{e}(\mathrm{k}-2)-0.1972 \mathrm{e}(\mathrm{k}-3)
\end{array}\right]\right\}+ \\
& {[1.933 \mathrm{u}(\mathrm{k}-1)-1.133 \mathrm{u}(\mathrm{k}-2)+0.2 \mathrm{u}(\mathrm{k}-3)]}
\end{aligned}
$$

This controller equation was described in the $\mathrm{C}$ language and inserted in the ISIS Proteus.
In Equation 11, we can observe that due to the order of the controller before the discretization, the discrete controller depends on three previous samples of input.

\section{Controller and linearized model}

A closed-loop system was simulated in Matlab, as illustrated in the Figure 3, with the linear controller and the linearized model of Ferrarin and Pedotti (Teixeira et al., 2007). Figure 4 shows the equivalent in the ISIS Proteus software, wherein the controller is embedded in a microcontroller.

\section{Controller and non-linear model}

In this section, we discuss the application of a linear controller designed with the linearized model and using the non-linear model of Ferrarin and Pedotti (2000). The system was simulated in Matlab and then in ISIS Proteus. The non-linear model more accurately reflects the relationship between electrical stimulation and the dynamics of knee extension movement.

\section{Test with a paraplegic volunteer}

An electric current with a balanced, biphasic, waveform with a frequency of $50 \mathrm{~Hz}$ was applied to the quadriceps muscle of the paraplegic volunteer while seated in the instrumented chair. The test objective was to induce muscle contraction and position the leg at a specified angle.

The closed-loop system used for the tests was as shown in Figure 3. The plant, which was simulated by a mathematical equation, was replaced by the quadriceps muscle of the volunteer.

The volunteer was informed of all procedures to be performed and read, completed and signed a consent form. The volunteer's blood pressure was measured during the tests.

A reference angle of $30^{\circ}$ was set in the microcontroller via software, and electrical stimulation was applied. The frequency and amplitude of the signal were the same as those used during the identification phase, but the pulse width was determined by the PID controller designed and embedded in the microcontroller.

\section{Results}

In all simulations and experimental tests, a step-type input was applied with an amplitude that provided an output steady state value equal to $30^{\circ}(0.52 \mathrm{rad})$.

\section{Linear controller and linear model}

The system responses with the linear controller and linear model of the paraplegic knee joint are shown in Figures 6a (Matlab) and 6b (ISIS Proteus). 


\section{Linear controller and linearized model}

Figures 7a (Matlab) and 7b (ISIS Proteus) illustrate the responses of the system with the linear controller and the linearized model of the paraplegic knee joint.

\section{Linear controller and non-linear model}

The system responses, with the linear controller and the non-linear plant of Ferrarin and Pedotti (2000), in Matlab and ISIS Proteus using the PIC18F4520 microcontroller are presented in Figure 8.

To illustrate the importance of the methodology described in this work, an example is shown in Figure 9 in which one bit of the register TMR responsible for the interrupt time and, consequently for the sampling period, should have a value of $0.01 \mathrm{~s}$, which is a feasible base time considering the microcontroller and the frequency of the electrical stimulation signal used in this work.

The sampling period is very important when a digital controller is used because many controller parameters are calculated according to this time base. In this example, the bit responsible by the interrupt was wrongly set to $0.02 \mathrm{~s}$ when it was written on the microcontroller. Consequently, as shown in Figure 9, the overshoot was greater than the specified value (20\%), but it could, in other situations, cause the system to become unstable.
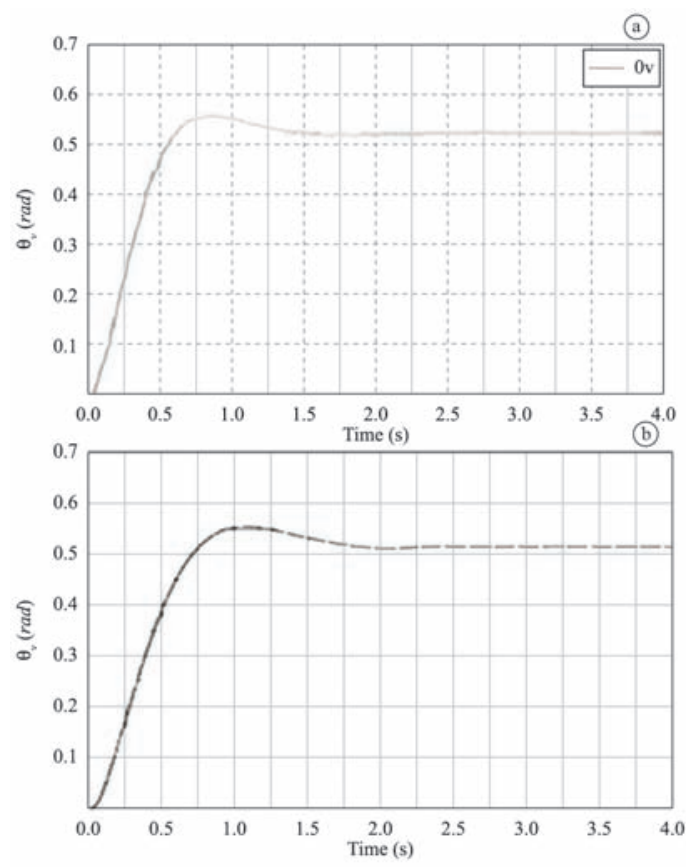

Figure 6. System responses to a step input of $30^{\circ}(0.52 \mathrm{rad})$ using a PID controller and linear plant, in Matlab (a) and ISIS Proteus (b).
When performing the simulation in ISIS Proteus, errors can be detected in the source code before the electrical stimulation is applied to the patient.

\section{Test with a paraplegic volunteer}

The results of an experimental test performed with the paraplegic volunteer are shown in Figure 10. The controller is described by Equation 2, using $\mathrm{Kp}=0.02685, \mathrm{Ki}=0.07794, \mathrm{Kd}=0.00046$, and Ts $=0.01 \mathrm{~s}$.

It can be observed that the responses of the experimental test and simulation presented results within the restrictions imposed: stability, for a steptype input, settling time of less than $2 \mathrm{~s}$, overshoot of less than $20 \%$, and null steady-state error.

\section{Discussion}

According to Ogata (2011), more than half of industrial controllers currently use PID controllers or modified versions of PID controllers. More recently, Cuoghi and Ntogramatzidis (2013) indicated that, according to recent and independent estimates, 95 to $97 \%$ of controllers used in many industrial processes belong to the family of PID controllers. Although they have a relatively simple structure, which facilitates the work of engineers in design and implementation, such controllers can be used in large portion of automatic control applications. Therefore, PID controllers are very important controllers
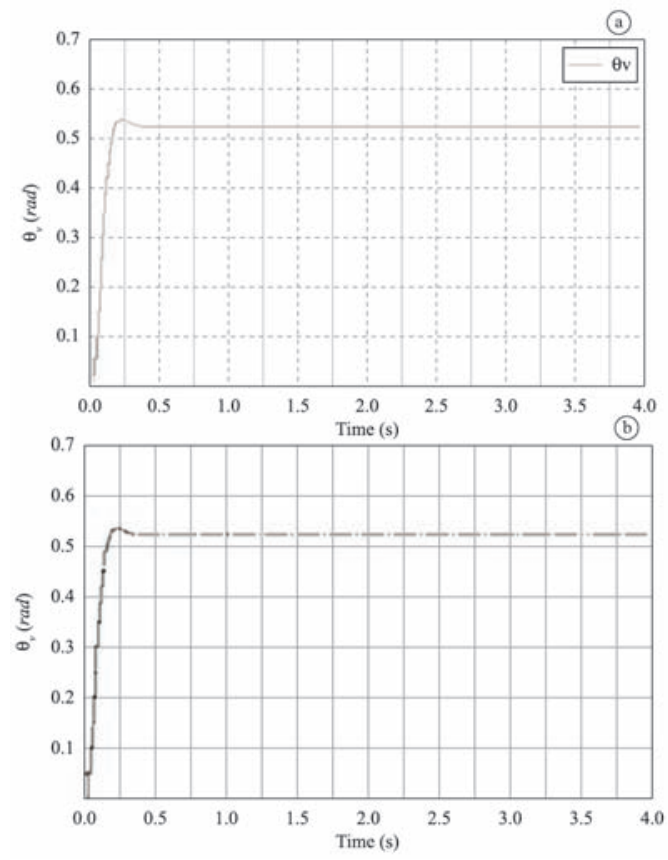

Figure 7. System responses to a step input of $30^{\circ}(0.52 \mathrm{rad})$ using a linear controller and linearized plant, in Matlab (a) and ISIS Proteus (b). 

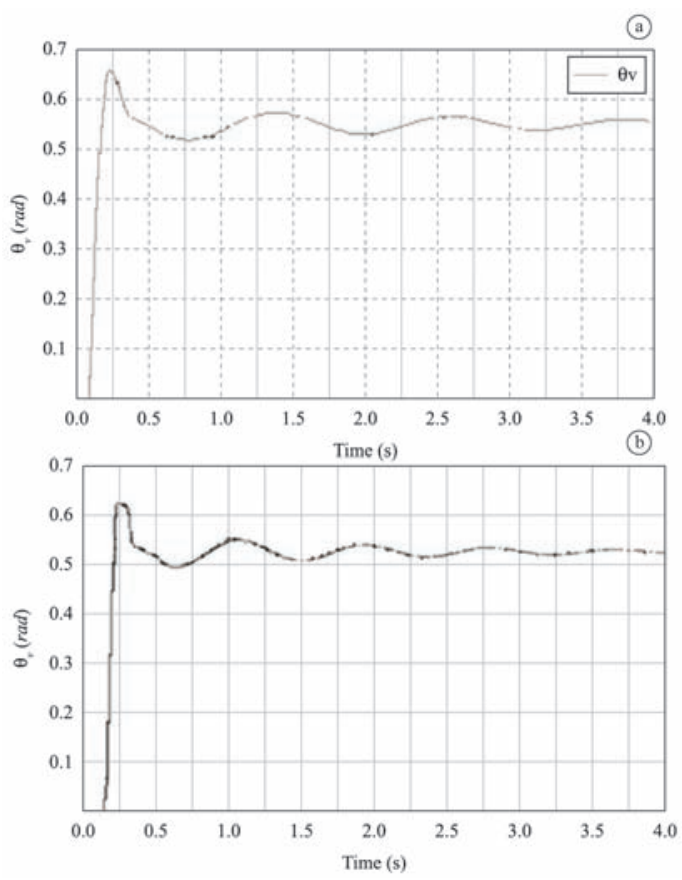

Figure 8. System responses to a step input of $30^{\circ}(0.52 \mathrm{rad})$ using a linear controller and non-linear plant, in Matlab (a) and ISIS Proteus (b).

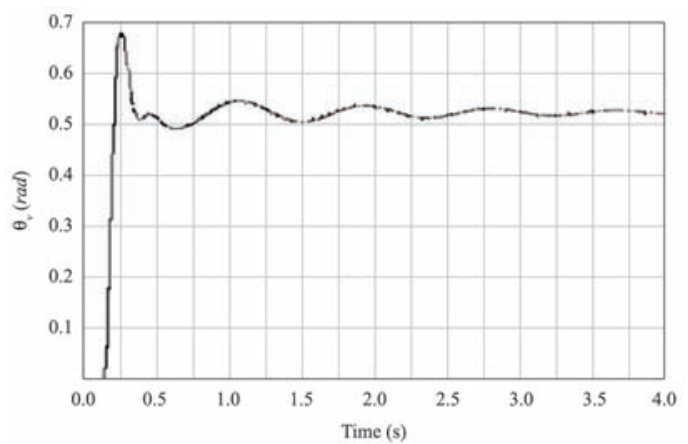

Figure 9. System response to a step input of $30^{\circ}(0.52 \mathrm{rad})$ using a linear controller and non-linear plant, due time error in the TMR register configuration.

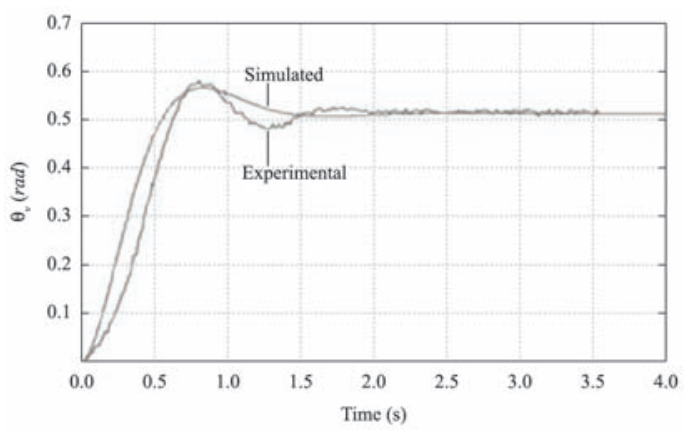

Figure 10. Responses of simulation and experimental test in a paraplegic volunteer. that are embedded in many industrial equipment to control processes, such as programmable logic controllers. Thus, PID controllers were chosen to carry out the research reported in this article.

Using the root locus method developed by Ogata (2011), a controller with three poles and three zeroes was also designed to make the study more comprehensive. It is worth mentioning that there are various other more sophisticated controllers that could have been used in this study, for example, controllers designed based on a non-linear plant model represented by Takagi-Sugeno fuzzy models, as described by Gaino (2009) and Teixeira et al. (2006). However, to obtain the desired performance, it was not necessary to resort to these more complex controllers.

The mathematical model that relates the electrical stimulation (input) to the volunteer leg's angle (output) is not linear (this fact can be proven as demonstrated by Ferrarin and Pedotti (2000)). In this study, we considered two mathematical models well known for the proposed system: a linear model estimated based on Law and Shields' paper (2006) and on experimental data of the response of a volunteer leg's angle after a step-type electrical stimulation and a linear model obtained by the linearization of the non-linear model proposed by Ferrarin and Pedotti (2000). Herein, we present simulations of the designed control systems considering the plant described by the two aforementioned linear models and by the non-linear model proposed by Ferrarin and Pedotti (2000), as well as the results obtained in a practical test with a paraplegic volunteer.

\section{Linear controller and knee joint linear model}

The response shown in Figure 6b, simulated in Proteus ISIS with a PIC18F4520 microcontroller, is similar to the response shown in Figure 6a, simulated in Matlab/Simulink. The response obtained with the ISIS Proteus software followed the design specifications, indicating that the hardware used is suitable for this implementation.

\section{Linear controller and linearized model of the knee joint}

The response shown in Figure 7a, simulated in Proteus ISIS with a PIC18F4520 microcontroller, and the response shown in Figure 7b, simulated in Matlab/ Simulink, are similar. Therefore, the hardware can be used to implement the designed controller.

\section{Linear controller and non-linear model of the knee joint}

It can be observed that the response of the controller designed using the non-linear model was different from the response obtained with the application of the 
linearized model of the plant. This result was expected, because according to Ogata (2011), the linear system exhibits the same behavior as the non-linear system only in a region very close to the operation point. However, by analyzing Figure 8, it is observed that the differences between the responses obtained with Matlab and ISIS Proteus were small, demonstrating the feasibility of the implementation of the hardware considered and of the control algorithm embedded in it. Although the controller was designed with the linearized model of the plant, in Figure 8 it is observed that the design specifications were met. Thus, the non-linearities of the plant neglected in the linearization process did not affect the response of the system.

The change in the sampling period of the correct value from $0.01 \mathrm{~s}$ to $0.02 \mathrm{~s}$ caused an overshoot greater than $20 \%$, beyond the design specification.

\section{Test with a paraplegic volunteer}

Using ISIS Proteus, it was possible to verify whether the A/D and D/A converters, PWM (Pulse Width Modulation), registers, clock crystal, embedded in the microcontroller, and other electronic components used were appropriate for the implementation of the controllers (Prado, 2009).

Using the ISIS Proteus software, it is possible to verify and correct details in the hardware of the controller before its practical implementation.

There are a wide variety of microcontrollers available in the market with different characteristics and prices, which could be used to implement the controller of the position of the paraplegic volunteer's leg, for example, the PIC16F877 (with a maximum operating frequency of $20 \mathrm{MHz}, 10$-bit A/D converters, and 8-bit bus), the PIC18F4520 (with a maximum operating frequency of $48 \mathrm{MHz}, 10$-bit A/D converters, and 8-bit bus), and the DSPIC33FJ32GP204 (with a maximum operating frequency of $900 \mathrm{MHz}, 12$-bit and 16-bit A/D converters). The proposed method allows for the verification that it is possible to implement the controller using a simpler microcontroller or whether a more sophisticated and higher-cost microcontroller is required.

Another important detail, after the choice of the microcontroller, is related to the source code to be embedded. If the source code has any error, the controlled system is unlikely to operate in accordance with the design specifications. The example shown in Figure 9, in which a bit of the TMR register was set incorrectly, illustrates this fact. In this case, the overshoot was greater than the specified value of $20 \%$ but could, in other situations, lead to system instability. Performing the simulation in ISIS Proteus, it is possible to detect and correct any inaccuracies in the source code before the electrical stimulation is applied to the patient.
The experimental response obtained with a paraplegic volunteer was very similar to the theoretical characteristics (Figure 10): rise time ( $0.25 \mathrm{~s}$ simulated and $0.35 \mathrm{~s}$ experimental), settling time ( $2.0 \mathrm{~s}$ simulated and $2.5 \mathrm{~s}$ experimental), overshoot percentage (18\% simulated and $19 \%$ experimental) and steady-state error (null in both cases). The differences between the experimental and theoretical responses can be attributed to several factors, including physiological factors, psychological factors, chair positioning, the plant chosen for the design, and parameter identification.

It should be emphasized that the experimental data were obtained using a signal conditioning circuit that has a low-pass fourth-order filter, which may cause a slight delay in the system response.

Using ISIS Proteus, it can be concluded that the chosen microcontroller and its programming were suitable for implementing a system to control the leg position of a paraplegic patient.

The methodology presented in this manuscript can contribute to the implementation of analog and digital controllers because hardware limitations are typically not taken into account in the design of controllers. The ISIS Proteus software emulates electronic devices and is able to reproduce the limitations of the components, allowing for the verification of whether the hardware components and the settings of its parameters are adequate to meet the requirements of the controller design.

The proposed procedure was successfully applied for the implementation of a controller used to control the leg position of a paraplegic volunteer by electrical muscle stimulation. The response obtained in the experiment with the patient complied with the established specifications in terms of stability, steadystate error, settling time and overshoot percentage.

\section{Acknowledgments}

The authors thank FAPESP, CNPq and CAPES for the financial support received to make this research possible.

\section{References}

Andreoni G, Ferrigno G, Baroni G, Colford NA, Bracciaferri F, Pedotti A. Postural modification in microgravity. In: Proceedings of the 5th European Symposium of Life Sciences Research in Space; 1996 June 16-20; Trondheim, Norway. p. 99-103. (ESA SP-390).

Blog do Deficiente Físico. Resultado do Censo 2010 feito pelo IBGE sobre pessoas com deficientes. [acesso em 2012 nov 15]. Disponível em: http://www.deficientefisico.com/ resultados-do-censo-2010-feito-pelo-ibge-sobre-pessoascom-deficiencia

Bobet J, Stein RB. A simple model of force generation by skeletal muscle during dynamic isometric contractions. IEEE Transactions on Biomedical Engineering. 1998; 45(8):10106. PMid:9691575. http://dx.doi.org/10.1109/10.704869 
Crago PE, Mortimer JT, Peckham PH. Closed-loop control of force during electrical stimulation of muscle. IEEE Transactions on Biomedical Engineering. 1980; 27(6):306-12. PMid:7390527. http://dx.doi.org/10.1109/ TBME.1980.326738

Cuoghi S, Ntogramatzidis L. Direct and exact methods for the synthesis of discrete time PID controllers. IET Control Theory and Applications. 2013; 7(18):2164-71. http://dx.doi. org/10.1049/iet-cta.2013.0064

Deaecto GS. Projeto e simulações de sistemas de controle utilizando modelo fuzzy e LMI [monografia]. Ilha Solteira: Universidade Estadual Paulista; 2005.

Ferrarin M, Pedotti A. The relationship between electrical stimulus and joint torque: a dynamic model. IEEE Transactions on Rehabilitation Engineering. 2000; 8(3):34252. http://dx.doi.org/10.1109/86.867876

Ferrarin M, Palazzo F, Riener R, Quintern, J. Modelbased control of FES-induced single joint Movements. IEEE Transactions on Neural Systems and Rehabilitation Engineering. 2001; 9(3):245-57. PMid:11561660. http:// dx.doi.org/10.1109/7333.948452

Franklin GF, Powell JD, Workman ML. Digital control of dynamic systems. Massachussets: Addison-Wesley Publishing Company; 2006.

Gaino R, Silva TI, Sanches MAA, Freitas RLB, Sato FH, Santos EA, Carvalho AA, Teixeira MM, Assunção E, Machado ERMD. Controle digital para fes no estímulo do músculo quadríceps em pacientes paraplégicos. In: Brazilian Conference on Dynamics, Control and Their Applications; 2007; São José do Rio Preto. p. 764-71.

Gaino R, Carvalho AA, Sanches MAA, Teixeira MCM, Neto JBC, Assunção E, Prado TA. Integração de controle e instrumentação com a utilização do software proteus para controle de movimentos na reabilitação de paraplégicos. In: V Congreso Iberoamericano de Tecnologías de Apoyo a la Discapacidad (IBERDISCAP); 2008; Cartagena de Índias, Colômbia.

Gaino R. Controle de movimentos de pacientes paraplégicos utilizando modelos Fuzzy Takagi-Sugeno [tese]. Ilha Solteira: Universidade Estadual Paulista; 2009.

Gaino R, Teixeira MCM, Carvalho AA, Assunção E, Covacic M, Cardim R, Sanches MAA. Realimentação derivativa e modelo fuzzy Takagi-Sugeno para controle da articulação do joelho de pacientes paraplégicos com o uso de acelerômetros. Revista Brasileira de Engenharia Biomédica. 2011; 27(2):67-78. http://dx.doi.org/10.4322/ rbeb.2011.006
Griffin BN. Design guide: the influence of zero-G and acceleration on the human factors of spacecraft design. Houston: NASA Johnson Space Center, 1978. (Internal note n. 14581).

Hatze H. Myocybernetic control models of skeletal muscle. Pretoria: University of South Africa Press; 1981.

Huxley AF. Muscle structure and theories of contraction. Progress in Biophysics and Biophysical Chemistry. 1957; 7:255-318. PMid:13485191.

Law LAF, Shields RK. Predicting human chronically paralyzed muscle force: a comparison of three mathematical models. Journal of Applied Physiology. 2006; 100(3):1027-36.

Lieber RL, Silva PD, Daniel DM. Equal effectiveness of electrical and volitional strength training for quadriceps femoris muscles after anterior cruciate ligament surgery. Journal of Orthopaedic Research. 1996; 14(1):131-8. PMid:8618155. http://dx.doi.org/10.1002/jor.1100140121

Mohammed S, Poignet P, Fraisse P, Guiraud D. Lower limbs movement restoration using input-output feedback linearization and model predictive control. In: IEEE International Conference on Intelligent Robots and Systems; 1997; San Diego, USA. p. 1945-50.

Ogata, K. Engenharia de controle moderno. São Paulo: Pearson Education; 2011.

Prado TA. Implementação de um controlador PID embarcado para o controle em malha fechada de um estimulador neuromuscular funcional [dissertação]. Ilha Solteira: Universidade Estadual Paulista; 2009.

Sanches MAA, Carvalho AA, Teixeira MCM, Gaino R, Prado TA, Pontes W, Santos EA, Freitas RLB, Gaino R. Projeto de controladores digitais utilizando microcontroladores e o software Isis Proteus. In: Congresso Brasileiro de Automática; 2010; Bonito, Brasil. p. 4752-6.

SCI-INFO. Spinal cord injury facts \& statistics. 2009. [acesso em 2011 set 2]. Disponível em: http://www.sciinfo-pages.com/facts.html

Teixeira MCM, Deaecto GS, Gaino R, Assunção E, Carvalho AA, Farias UC. Design of a fuzzy Takagi-Sugeno controller to vary the joint knee angle of paraplegic patients. Lectures Notes in Computer Science Springer. 2006; 4234(3):118-26. http://dx.doi.org/10.1007/11893295_14

Teixeira MCM, Deaecto GS, Gaino R, Assunção E, Carvalho AA, Machado ERMD, Silva TI. Projeto de um controlador linear para variar o ângulo de articulação do joelho de um paciente paraplégico. In: Brazilian Conference on Dynamics, Control and Their Applications; 2007; São José do Rio Preto. p. 950-6. PMid:17469087.

\section{Authors}

\section{Marcelo Augusto Assunção Sanches, Renan Fernandes Kozan, Marcelo Carvalho Minhoto Teixeira, Aparecido Augusto de Carvalho, Carlos Antonio Alves, Mateus Fernandes Réu Urban, Marcos Vinícius Nascimento Junqueira, Rodrigo Cardim, Edvaldo Assunção}

Department of Electrical Engineering, Universidade Estadual Paulista - UNESP, Campus of Ilha Solteira, Ilha Solteira, SP, Brazil

\section{Ruberlei Gaino*, Márcio Roberto Covacic, Edno Gentilho Junior}

Department of Electrical Engineering - DEEL, Center of Technology and Urbanism - CTU, Londrina State University - UEL, Rodovia Celso Garcia Cid, Km 380 PR 445, CEP 86057-970, Londrina, PR, Brazil 